\title{
Long-Term Potentiation in the Visual Cortex Requires Both Nitric Oxide Receptor Guanylyl Cyclases
}

\author{
Arash Haghikia, ${ }^{1 *}$ Evanthia Mergia, ${ }^{2 *}$ Andreas Friebe, ${ }^{2}$ Ulf T. Eysel, ${ }^{1}$ Doris Koesling, ${ }^{2}$ and Thomas Mittmann ${ }^{1}$ \\ ${ }^{1}$ Faculty of Medicine, Institute of Physiology, Department of Neurophysiology, and ${ }^{2}$ Faculty of Medicine, Institute of Pharmacology and Toxicology, \\ Ruhr-University Bochum, D-44780 Bochum, Germany
}

The role of nitric oxide (NO)/cGMP signaling in long-term potentiation (LTP) has been a lingering matter of debate. Within the cascade, the NO receptor guanylyl cyclase (GC), the cGMP-forming enzyme that is stimulated by NO, plays a key role. Two isoforms of GC $\left(\alpha_{2}-\mathrm{GC}\right.$, $\alpha_{1}$-GC) exist. To evaluate their contribution to synaptic plasticity, we analyzed knock-out mice lacking either one of the GC isoforms. We found that LTP induced in the visual cortex is NO dependent in the wild-type mice, absent in either of the GC isoform-deficient mice, and restored with application of a cGMP analog in both strains. The requirement of both NO receptor GCs for LTP indicates the existence of two distinct NO/cGMP-mediated pathways, which have to work in concert for expression of LTP.

Key words: LTP; visual cortex; NO; guanylyl cyclase; cGMP; KO

\section{Introduction}

The signaling molecule nitric oxide (NO) has been postulated to participate in long-term potentiation (LTP), the use-dependent increase of transmission efficacy at synapses implicated in learning and memory (for review, see Hawkins et al., 1998; Garthwaite and Boulton, 1995). Already, initial reports suggested NO as a retrograde messenger synthesized in response to NMDA receptor activation in the postsynaptic neuron and causing long-lasting increases of transmitter release in the presynaptic terminals (Garthwaite et al., 1988; O’Dell et al., 1991; Schuman and Madison, 1991). Other studies performed mainly in hippocampal slices of the CA1 region revealed that NO is not involved in all forms of LTP but only in certain areas and under special experimental conditions (Son et al., 1998). Additional conformation for NO-dependent LTP was obtained in the stratum radiatum of the CA1 field of the hippocampus in NO synthase (NOS)deficient mice (Son et al., 1996; Wilson et al., 1997, 1999).

Most of the effects of $\mathrm{NO}$ as a signaling molecule are mediated by the activation of the NO receptor guanylyl cyclase (GC) (Bellamy and Garthwaite, 2002; Koesling et al., 2004), the enzyme which by the formation of cGMP and the resulting activation of cGMP-regulated effector molecules (protein kinases, ion channels, phosphodiesterases) passes on the NO signal. Two isoforms of the NO receptor GC exist: the major occurring $\alpha_{1}$-GC and the less abundant $\alpha_{2}$-GC consisting of either the $\alpha_{1}$ or $\alpha_{2}$ subunit dimerized to a common $\beta$ subunit, respectively (Russwurm et al.,

Received 0ct. 30, 2006; revised Dec. 18, 2006; accepted Dec. 22, 2006.

This work was supported by the Deutsche Forschungsgemeinschaft (A.F. and D.K.) and Sonderforschungsbereich Grant 509 and Graduiertenkolleg Grant 736 (U.E. and T.M.) We thank Medah Özcan and Petra Küsener for excellent technical assistance and Stefan Offermans and his group for providing the transgene Ella-mice.

*A.H. and E.M. contributed equally to this work.

Correspondence should be addressed to Doris Koesling, Faculty of Medicine, Institute of Pharmacology and Toxicology, Ruhr-University Bochum, D-44780 Bochum, Germany. E-mail: doris.koesling@ruhr-uni-bochum.de. DOI:10.1523/JNEUROSCI.4706-06.2007

Copyright $\odot 2007$ Society for Neuroscience $\quad$ 0270-6474/07/270818-06\$15.00/0
1998; Mergia et al., 2003). The isoforms appear to be very similar as they do not differ in regulatory or enzymatic properties. However, the $\mathrm{C}$ terminus of $\alpha_{2}$-GC allows an interaction with the synaptic adaptor protein PSD-95 (postsynaptic density-95), indicating a synaptic localization (Russwurm et al., 2001). The possible neuronal function of this isoform is supported by its high expression in the brain compared with other tissue. Nevertheless, the $\alpha_{1}$-GC is also present in brain in similar amounts (Mergia et al., 2003). In accordance with the assumption that the GC acts as a receptor for NO to mediate enhancement of synaptic transmission, the inhibitor of NO receptor GC, $1 H$-[1,2,4] oxadiazolo [4,3-a]-quiloxalin-1-one (ODQ), blocks LTP induction in the hippocampal CA1 region (Boulton et al., 1995) and perfusion with a cGMP analog plus weak tetanic stimulation in some experimental settings produces LTP (for review, see Son et al., 1998). In contrast, application of cGMP analogues or NO alone is not able to induce LTP, implying that the activity in the NO/ cGMP pathway has to be synchronized to other events in presynaptic terminals or in postsynaptic elements (Bon and Garthwaite, 2002).

Here, we used knock-out (KO) mice deficient in either one of the GC isoforms to study the role of NO receptor GC in the enhancement of synaptic transmission. LTP measured in the visual cortex of wild-type (WT) mice was almost completely cGMP dependent, as shown by the inhibition by ODQ. Unexpectedly, LTP was absent in either one of the GC isoform-deficient mice but was restored by application of an cGMP analog paired with theta-burst stimulation (TBS). We conclude that both GC isoforms are required for LTP, indicating two distinct NO/cGMPmediated pathways involved in the triggering of LTP.

\section{Materials and Methods}

KO animals. Generation and genotyping of the $\alpha_{1}$ - or $\alpha_{2}$-KO mice has been described previously by Mergia et al. (2006). Briefly, exon 4 of the $\alpha_{1}$ or $\alpha_{2}$ subunits floxed by loxP-sites $\left(\alpha_{1}{ }^{+/ f l o x}\right.$ and $\left.\alpha_{2}{ }^{+/ f l o x}\right)$ were removed by crossing with the general deleter mouse EIIa-Cre, respectively. The 
resulting heterozygous $\mathrm{KO}$ mice were crossed with WT mice (C57BL/6) to remove the Cre recombinase gene. Finally, the generated heterozygotes were intercrossed to yield homozygous mice ( $\alpha_{1}-\mathrm{KO}$ and $\left.\alpha_{2}-\mathrm{KO}\right)$.

Studies were performed with 6- to 10 -week-old mice of either sex derived from hybrid parents $(129 / \mathrm{SvJ} \times \mathrm{C} 57 \mathrm{BL} / 6)$ backcrossed three or four times (F3-F4 generation). In the experiments, either litter- or agematched mice of the same sex were used wherever feasible.

Electrophysiological recordings. All experiments were performed in accordance with the guidelines of the local animal ethics commission and German laws. The animals were deeply anesthetized with ether and decapitated. The brains were rapidly removed and kept in ice-cold artificial CSF (ACSF) containing the following (in $\mathrm{mM}$ ): $125 \mathrm{NaCl}, 2.5 \mathrm{KCL}, 1.25$ $\mathrm{NaH}_{2} \mathrm{PO}_{4}, 25 \mathrm{NaHCO}_{3}, 25$ D-glucose, $2 \mathrm{CaCl}_{2}$, and $1.5 \mathrm{MgCl}_{2}$, bubbled with $95 \% \mathrm{O}_{2}$ and $5 \% \mathrm{CO}_{2}$ to $\mathrm{pH}$ 7.4. Coronal slices of $350 \mu \mathrm{m}$ thickness were cut from the visual cortex using a vibratome (VT 1000 S; Leica, Nussloch, Germany). Slices were placed in a holding chamber and incubated with oxygenated ACSF at room temperature. The slices recovered for at least $1 \mathrm{~h}$ before they were transferred to a submerged recording chamber mounted on the stage of an upright microscope (BX50-WI; Olympus, Tokyo, Japan) equipped with a $2.5 \times$ objective (numerical aperture, 0.075; Zeiss, Oberkochen, Germany). The recording chamber was superfused with oxygenated ACSF at $32 \pm 2^{\circ} \mathrm{C}$. A concentric bipolar stimulation electrode was placed in layer IV delivering monophasic current pulses of $100 \mu$ s duration and intensities of $80-150 \mu \mathrm{A}$. Extracellular field potentials (FPs) were recorded using electrodes pulled from borosilicate glass capillaries (GB 150-8P; Science Products, Hofheim, Germany), which were filled with ACSF (resistance, 1-3 M $\Omega$ ). The FPs were low-pass filtered at $3 \mathrm{kHz}$ and amplified with a differential amplifier (EPMS07; NPI Electronics, Tamm, Germany). Traces were sampled offline using Clampex 9.2 (Molecular Devices, Union City, CA). The FP amplitude was measured as the maximal negative orthodromic voltage after the stimulus. Input-output relation of FPs was calculated by determining the stimulus intensity that evoked a saturated maximal FP amplitude. For the recordings, this intensity was kept constant, while the stimulus duration was varied from 40 to $200 \mu$ s in steps of $20 \mu$ s. Only slices which produced a maximal FP amplitude of at least $1.2 \mathrm{mV}$ were selected for additional evaluation. For LTP experiments, the stimulus intensity was adjusted to elicit $40-60 \%$ of the maximal response amplitude and kept constant throughout the experiment. Baseline synaptic responses were recorded every $30 \mathrm{~s}$ for at least $30 \mathrm{~min}$ before tetanic stimulation. The recording was discarded if the baseline FP amplitude was not stable for $30 \mathrm{~min}$ and/or if the reproducible maximal FP amplitude was $<1 \mathrm{mV}$. TBS consisted of three trains delivered at $0.1 \mathrm{~Hz}$, each train consisting of 10 bursts at $5 \mathrm{~Hz}$, each burst delivering four stimuli at $100 \mathrm{~Hz}$ with a $200 \mu$ s stimulus duration. Changes in FP amplitudes were calculated in relation to the baseline FP responses during the last $10 \mathrm{~min}$ before TBS (100\%). The time course of the FP responses was then normalized to this baseline and averaged across experiments. Long-term synaptic changes were evaluated by the averaged 20 responses at 51-60 min post-TBS as compared with the averaged 20 baseline signals before TBS. The following compounds were prepared as stock solutions and diluted in the perfusion medium at the desired concentration immediately before the experiment: D-AP5 (Tocris Bioscience, Ellisville, MO), 8-(4-chlorophenylthio) (8-pCPT)-cGMP (Biolog, Bremen, Germany), and ODQ (Sigma, Muenchen, Germany). Neither of the compounds led to alterations of the baseline FP signals (data not shown).

Statistical analysis. All data are presented as means \pm SEM. Student's $t$ and Mann-Whitney $U$ test were performed for statistical analysis of the data. Unless stated otherwise, $p$ values represent significance of the data compared with baseline.

Western blots. Brains or visual cortex were removed after decapitation and homogenized immediately in buffer $(50 \mathrm{~mm}$ triethanolamine/ $\mathrm{HCl}$, $50 \mathrm{~mm} \mathrm{NaCl}, 1 \mathrm{~mm}$ EDTA, $2 \mathrm{~mm}$ DTT, $0.2 \mu \mathrm{m}$ benzamidine, $0.5 \mu \mathrm{M}$ PMSF, and $1 \mu \mathrm{M}$ pepstatin $\left.\mathrm{A}, \mathrm{pH} 7.4,4^{\circ} \mathrm{C}\right)$. After centrifugation $(800 \times g$, $5 \mathrm{~min}, 4^{\circ} \mathrm{C}$ ), homogenates were subjected to Western blot analysis performed as described previously by Mergia et al. (2006). The protein concentration was determined in triplicates and repeated three times (Bradford; Bio-Rad, Hercules, CA). Antibodies against endothelial (eNOS-9D10) and neuronal NOS (polyclonal antibodies generated against purified nNOS from pig brain) were from Invitrogen (Eugene, $\mathrm{OR}$ ) and Alexis (Lausen, Switzerland), respectively.

Determination of cGMP-forming activities. Homogenates obtained as described above were used to measure NO-stimulated cGMP-forming activities as described by Mergia et al. (2006).

Determination of cGMP content in the visual cortex. Coronal slices (350 $\mu \mathrm{m})$ were cut from the visual cortex and equilibrated as described above. Slices were incubated with the phosphodiesterase inhibitor IBMX (1 mM; Sigma) for $10 \mathrm{~min}$ at $32 \pm 2^{\circ} \mathrm{C}$. Subsequently, either a TBS stimulus was applied, or the slices were incubated in the absence or presence of 2 -( $N, N$,-diethylamino)-diazenolate-2-oxide (DEA-NO) (10 $\mu \mathrm{M}$; Alexis) for an additional $5 \mathrm{~min}$. To extract cGMP, slices were snap frozen in liquid nitrogen, homogenized in $70 \%(\mathrm{v} / \mathrm{v})$ ice-cold ethanol using a glass/ glass homogenizer, and then centrifuged $\left(14,000 \times \mathrm{g}, 15 \mathrm{~min}, 4^{\circ} \mathrm{C}\right)$. Supernatants were dried at $95^{\circ} \mathrm{C}$ and the cGMP content was measured by RIA. To standardize the different samples, protein pellets were dissolved in $0.1 \mathrm{M} \mathrm{NaOH} / 0.1 \%$ SDS and the protein content was determined using the bicinchoninic acid method (Uptima, Montlucon, France).

\section{Results}

\section{KO mice lacking either one of the NO receptor GCs}

Two isoforms of NO receptor GC $\left(\alpha_{1}-\mathrm{GC}, \alpha_{2}-\mathrm{GC}\right)$ exist. Isoform-deficient $\mathrm{KO}$ mice were generated by deleting either one of the $\alpha$ subunits. Both strains $\left(\alpha_{1}-\mathrm{KO}, \alpha_{2}-\mathrm{KO}\right)$ do not show any reduction of life expectancy or obvious behavioral abnormalities (Mergia et al., 2006). Western blot analysis of the GC subunits in the brain of WT and KO mice confirmed the lack of the $\alpha_{1}$ or $\alpha_{2}$ subunit in the respective KO strain (Fig. 1A). Furthermore, the amount of the nondeleted $\alpha$-subunit in either KO strain was similar to that in WT mice, demonstrating that deletion of one GC isoform does not lead to an enhanced expression of the remaining one. NO-stimulated cGMP formation determined in brain homogenates of the $\alpha_{1}$-deficient and $\alpha_{2}$-deficient $\mathrm{KO}$ strains was in a comparable range, indicating similar amounts of both isoforms in brain $\left(\alpha_{1}-\mathrm{KO}, 0.5 \pm 0.1 ; \alpha_{2}-\mathrm{KO}, 0.9 \pm 0.2\right.$; WT, $1.4 \pm 0.1 \mathrm{nmol} \mathrm{cGMP} / \mathrm{mg} / \mathrm{min} ; n=5$ of each genotype).

\section{Members of the NO/cGMP signaling cascade in the visual cortex}

Next, we studied expression of the GC subunits $\left(\alpha_{1}, \alpha_{2}, \beta_{1}\right)$ in the visual cortex (Fig. $1 B$ ). Because all subunits were detected, we conclude that indeed both GC isoforms, $\alpha_{1}$-GC and $\alpha_{2}$-GC, occur in the visual cortex. Moreover, with antibodies against the NO-forming enzymes, we identified neuronal as well as endothelial NOS in the visual cortex slices (Fig. $1 B$ ) underlining the possible role of NO/cGMP signaling in synaptic transmission in this brain region. Functionally, we confirmed the occurrence of NO receptor GCs in visual cortex slices by measuring the cGMP content in the absence and presence of exogenous NO (Fig. 1C). The cGMP levels under nonstimulated conditions as well as NOinduced cGMP increases (from 7 up to $40 \mathrm{pmol} \mathrm{cGMP/mg}$ ) exactly matched those measured in the hippocampus, underscoring the significance of the NO/cGMP cascade in the visual cortex (Bon and Garthwaite, 2001). Cyclic GMP levels determined subsequent to LTP induction using TBS did not show any significant increases.

\section{FP recordings in the visual cortex}

After detecting NOSs and GC isoforms in the visual cortex, we studied the possible functional role of NO/cGMP signaling in synaptic plasticity. First, basal excitatory synaptic transmission in cortical slices prepared from WT, $\alpha_{1}$ - and $\alpha_{2}$-deficient mice was analyzed by recording AMPA receptor-dominated FP responses in cortical layer III to electrical stimulation of layer IV with con- 
A

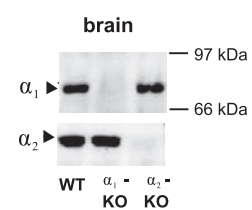

C
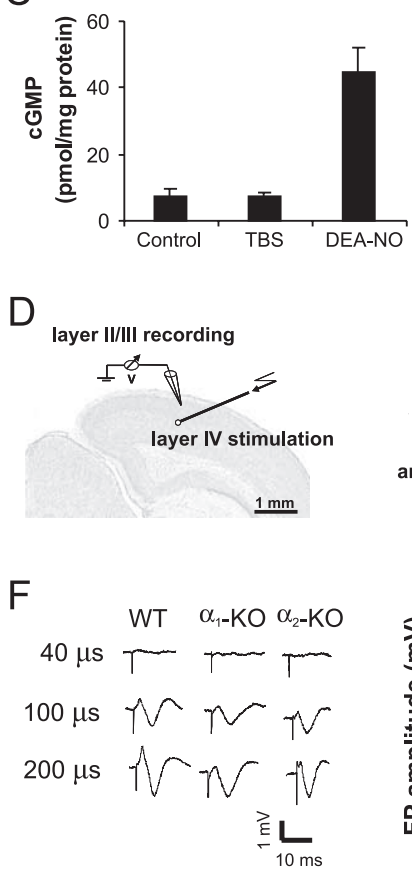

B

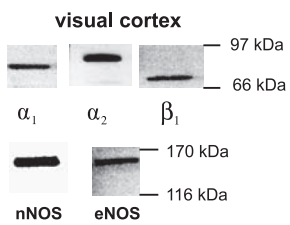

E

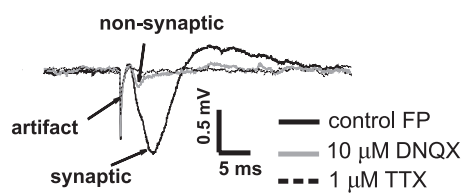

Figure 1. Targeted deletion of $\mathrm{GC}$ isoforms in mice does not alter basal synaptic transmission in visual cortex. $\boldsymbol{A}$, Western blot analysis of the $\alpha_{1}$ and $\alpha_{2}$ subunits of N0-sensitive GC in brain of WT, $\alpha_{1}$-, and $\alpha_{2}$-deficient animals was performed as described in Materials and Methods. $\boldsymbol{B}$, Both GC isoforms as well as the endothelial and neuronal NOSs are expressed in the visual cortex. Shown is a representative experiment. C, Cyclic GMP levels were determined in slices of the visual cortex incubated with IBMX (1 $\mathrm{mm}, 10 \mathrm{~min}$.) without additional treatment ( 8 slices form 4 mice), after TBS ( 6 slices from 4 mice), and in the presence of DEA-NO ( $10 \mu \mathrm{m}, 5 \mathrm{~min}$; 9 slices from 2 mice) as outlined in Materials and Methods. D, Nissl-stained slice of the visual cortex with the recording electrode located in layer III and the stimulation electrode in layer IV. $\boldsymbol{E}$, The synaptically evoked FP is blocked in the presence of $10 \mu \mathrm{m}$ DNQX; the remaining nonsynaptic component is abolished by $1 \mu \mathrm{M}$ TTX. $\boldsymbol{F}$, Representative example traces of FPs recorded at stimulus durations of 40, 100, and $200 \mu$ s for each experimental group (left). Input-output relationship (right) of stimulus-evoked FP responses to gradually increasing stimulus durations in WT (9 slices from 6 mice), $\alpha_{1}$-KO ( 9 slices from 3 mice), and $\alpha_{2}$-KOs ( 10 slices from 4 mice).

stant intensities and various durations (Fig. $1 D-F)$. In all three experimental groups, short stimulus pulses $(40-80 \mathrm{~ms})$ elicited a small orthodromic FP response. An increase in stimulus duration evoked larger field responses with a maximum at a stimulus duration of $200 \mu \mathrm{s}$. The resulting input-output curves for all three groups (Fig. $1 F$ ) were similar and showed no alterations of basal synaptic transmission in the $\mathrm{KO}$ animals.

\section{Activity-dependent enhancement of synaptic transmission: a role of GC isoforms}

Next, the activity-dependent strengthening of synaptic transmission was analyzed in LTP experiments on WT mice (Fig. 2). TBS to ascending fibers located in layer IV led to significant LTP in the mean FP amplitude of neurons in cortical layer III (122.4 $\pm 3.3 \%$; $n=9 ; p<0.001)$. The strength of potentiation induced by TBS did not differ significantly between the WT littermates of the 2

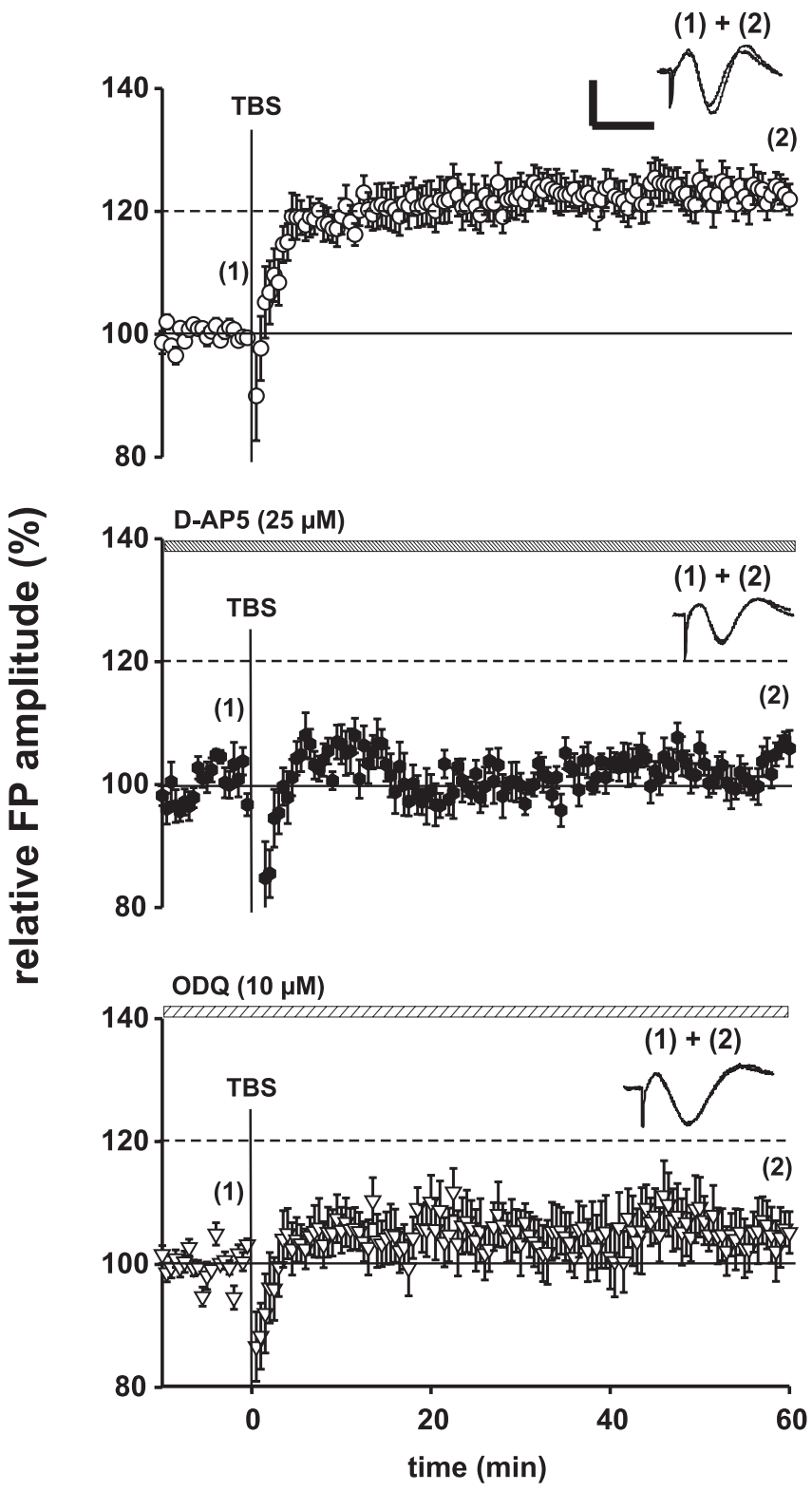

Figure 2. N0-dependency of LTP in visual cortex of mice. TBS-induced changes in relative FP amplitudes of murine visual cortical slices in the absence (top, 9 slices from 6 mice) and in the presence of the NMDA-receptor antagonist D-AP5 (middle, 8 slices from 3 mice). TBS fails to induce LTP in the presence of the inhibitor of NO-sensitive GC, ODQ (bottom, 8 slices from 4 mice). Representative FPs before (1) and after TBS (2) are shown. Calibration: $1 \mathrm{mV}, 10 \mathrm{~ms}$.

KO strains $(119 \pm 2 \%$ vs $131 \pm 8 \% ; p=0.11$ for differences between WT strains). In agreement with other studies performed in rodent visual cortex (Kirkwood et al. 1993; Huemmeke et al. 2004), the expression of LTP was blocked in the presence of the NMDA-receptor antagonist D-AP5 without affecting the shape of the baseline FP signal (Fig. 2, middle). In a set of separate experiments, we bath applied ODQ, an inhibitor of the NO receptor $\mathrm{GC}$, to test the possible involvement of the GC on the strength of LTP. ODQ $(10 \mu \mathrm{M})$ almost completely prevented a TBS-induced potentiation of FPs $(104.9 \pm 3.6 ; n=8 ; p=0.25)$, which indicates that NO-stimulated cGMP formation is essential for activity-dependent strengthening of synaptic transmission in the visual cortex (Fig. 2, bottom).

To identify the GC isoform involved, TBS-induced LTPs were recorded in cortical slices of the $\alpha_{1}$ - and $\alpha_{2}$-deficient KO mice. 

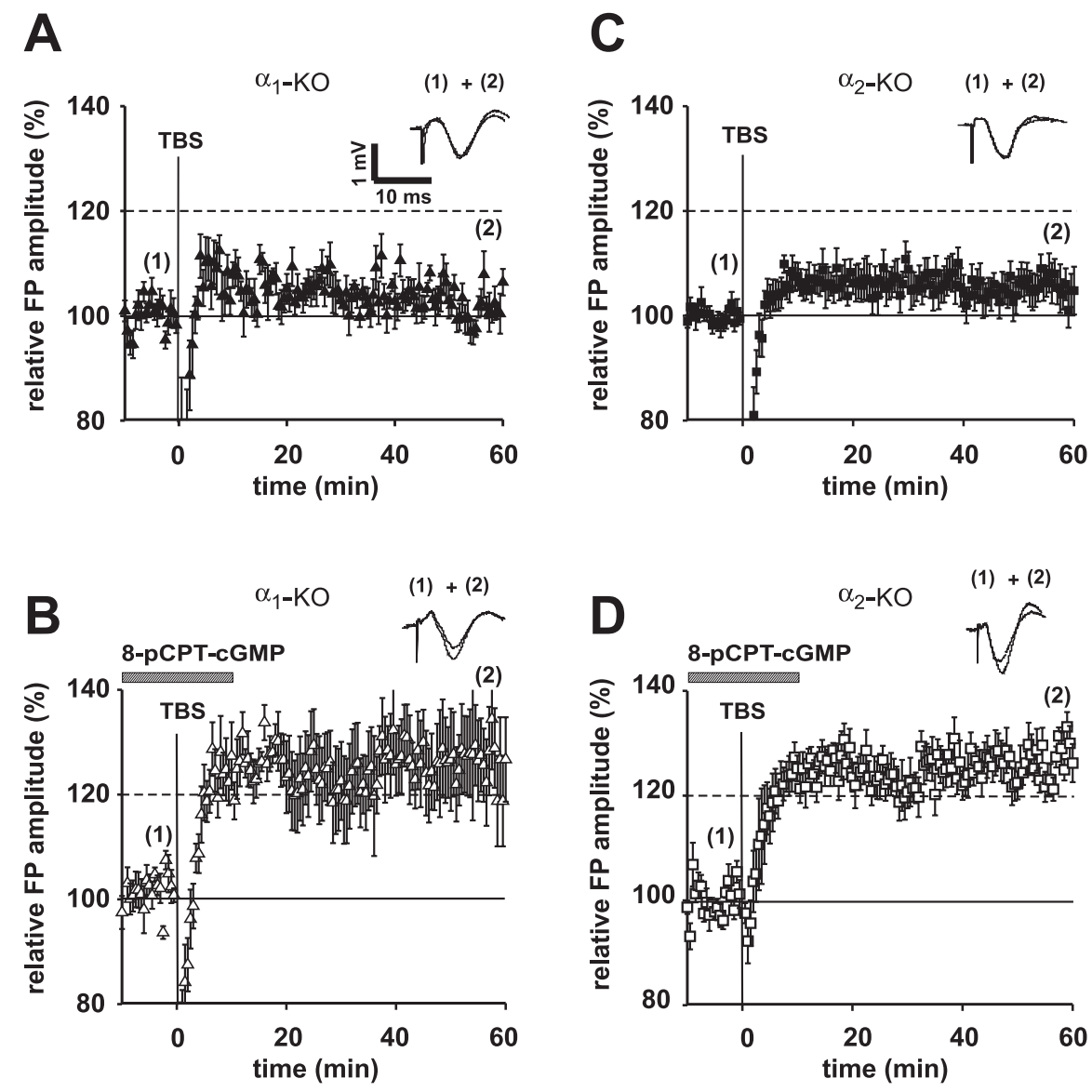

Figure 3. LTP is absent in the visual cortex of the $\alpha_{1}$ - and $\alpha_{2}$-KOs but can be restored with a GMP analog. $A, C$, TBS-induced changes in relative FP amplitudes of visual cortical slices of $\alpha_{1}-\mathrm{KOs}$ ( $\boldsymbol{A}, 7$ slices from 5 mice) and $\alpha_{2}-\mathrm{KO}$ s ( $\boldsymbol{C}, 9$ slices from 6 mice). $\boldsymbol{B}, \boldsymbol{D}$, Incubation of $\alpha_{1}$-deficient ( $\boldsymbol{B}, 7$ slices from 5 mice) and $\alpha_{2}$-deficient ( $\boldsymbol{D}, 7$ slices from 3 mice) slices with the GMP analog, 8-pCPT-cGMP $(10 \mu \mathrm{M})$, paired with TBS restored LTP. Representative FPs before (1) and after TBS (2) are shown above the respective diagram.

Much to our surprise, the TBS protocol failed to elicit LTP in either one of the KO strains (Fig. $3 A, C)\left(\alpha_{1}-\mathrm{KO}, 102.6 \pm 1.6 \%\right.$, $\left.n=6, p=0.2 ; \alpha_{2}-\mathrm{KO}, 105.8 \pm 2.9 \%, n=9, p=0.1\right)$.

In an attempt to compensate the impairment in NO/cGMP signaling, we bath-applied the cGMP analog 8-pCPT-cGMP (10 $\mu \mathrm{M})$. In WT slices, the cGMP analog did not affect the amplitude of basal FP-signals during our standard recording period of 90 min, nor did it cause a prominent increase of the strength of LTP when paired with a TBS (Fig. 4). In contrast, the cGMP analog rescued LTP induction after TBS in both, $\alpha_{1^{-}}$as well as $\alpha_{2^{-}}$ deficient cortical slices (Fig. $3 B, D)\left(\alpha_{1}-\mathrm{KO}, 124.5 \pm 6.8 \%, n=7\right.$, $\left.p=0.02 ; \alpha_{2}-\mathrm{KO}, 126.9 \pm 2.2 \%, n=7, p<0.001\right)$. These results demonstrate that exogenous cGMP can functionally substitute the cGMP produced by either one of the GC isoforms in LTP. More importantly, the successful LTP reconstitution rules out a general (e.g., developmentally caused) impairment of LTP in the GC KO animals. Thus, the lack of LTP in the KOs clearly demonstrates that the presence of both NO receptor GCs is mandatory for LTP expression in the visual cortex, indicating the involvement of the GC isoforms in distinct signaling pathways. Attempts to reconstitute LTP in the $\alpha_{1}$ - and $\alpha_{2}$-deficient slices with an NO donor ( 10 or $30 \mu \mathrm{M}$ DEA-NO) paired with TBS were unsuccessful (data not shown), which argues against a consecutive alignment of the NO/cGMP induced signals.

\section{Discussion}

The role of the NO/cGMP pathway in LTP is controversially discussed. Although some of the reported discrepancies may be explained by the experimental conditions such as the stimulation protocol, the brain region and the pharmacological tools used (NOS inhibitors, GC inhibitors, cGMP analogues, cGMP kinase inhibitors), it is now evident that $\mathrm{NO}$ is involved under particular conditions at certain hippocampal areas but not as a universal player in strengthening of synaptic transmission (Son et al., 1998). Experiments in NOS-deficient KO mice revealed that LTP induced by a weak stimulus in the CA1 field of the hippocampus is largely NOdependent. Which of the NOS isoforms is responsible for this $\mathrm{NO}$ effect is not quite clear, because an alteration of LTP was described in eNOS-deficient mice by one group (Wilson et al., 1997, 1999) and only in the double KOs (eNOS and nNOS) by others (Son et al., 1996). A previous paper supplies convincing evidence that tonic and phasic NO signals generated by eNOS and $\mathrm{nNOS}$, respectively, are required for hippocampal LTP (Hopper and Garthwaite, 2006).

The major effects of $\mathrm{NO}$ as a signaling molecule are mediated by NO receptor $\mathrm{GC}$, the cGMP-forming enzyme that is activated by NO binding to its prosthetic heme group. NO receptor GC is considered as a single enzyme, and very little attention has been paid to the existence of two GC isoforms. Because the purified GC isoforms exhibit indistinguishable catalytic and regulatory properties, the physiological relevance of two similarly regulated isoforms was unclear. However, the ability of the $\alpha_{2}$-containing GC to interact with synaptic adaptor proteins like PSD-95 suggests a particular synaptic localization of this isoform.

KO mice deficient in either one of the NO receptors, $\alpha_{1}-\mathrm{GC}$ or $\alpha_{2}$-GC, provide for the first time the opportunity to study the role of the NO receptor GCs in LTP in a nonpharmacological manner and identify the responsible isoforms. In the present study, we used visual cortical slices in which LTP had been reported previously (Artola and Singer, 1987; Kirkwood et al. 1993; Bear, 1995; Huemmeke et al. 2004). As shown by Western blot analysis, both $\mathrm{GC}$ isoforms are expressed in the visual cortex as are both NOproducing enzymes, eNOS and nNOS. Moreover, the cGMP amount measured in NO-incubated slices of the visual cortex was almost the same as that in the hippocampal CA1 region, indicating comparable amounts of NO receptor GC in both brain areas. The distribution of NO receptor GC in the cerebral cortex has been studied by immunohistochemistry. With antibodies recognizing both GC isoforms, GC staining was most pronounced in pyramidal neurons and observed through all cortical layers (Ding et al., 2005); nNOS was reported to colocalize not in the same, but in adjacent cells (Ding et al., 2004). Occurrence of both GCs in the cerebral cortex was confirmed using isoform-specific anti- 


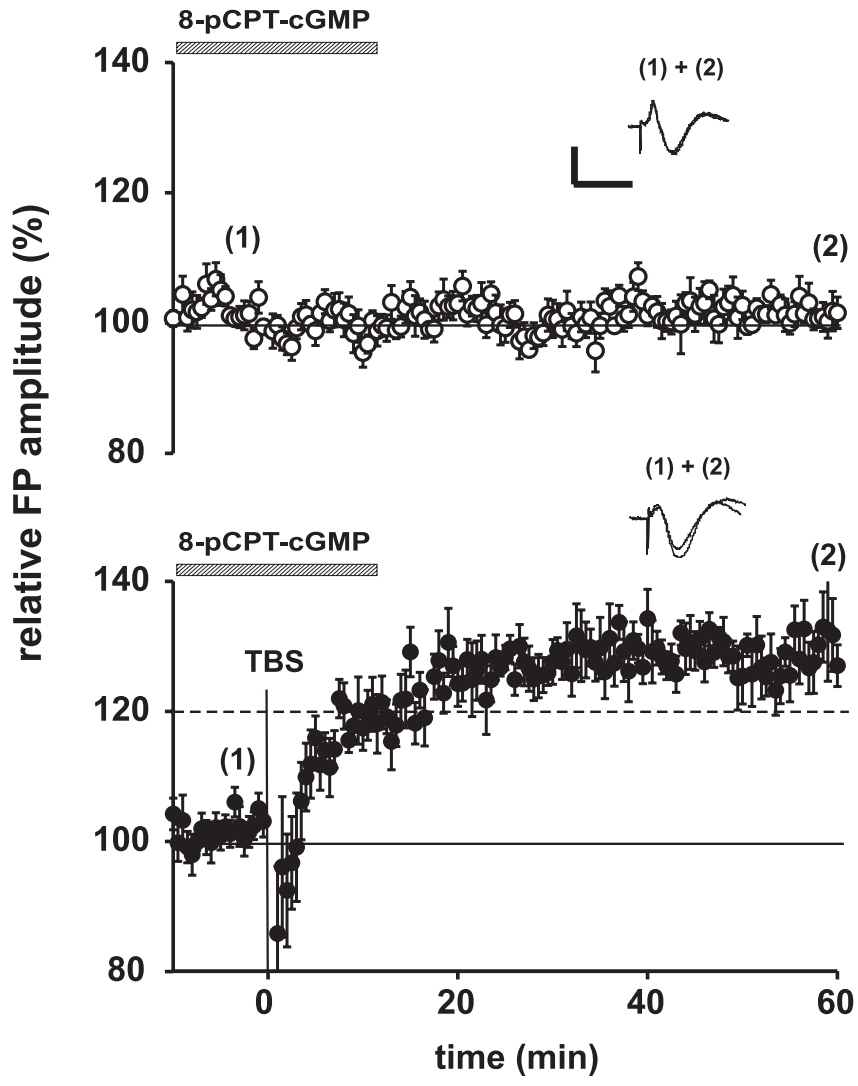

Figure 4. The cGMP analog, 8-pCPT-cGMP, neither affects basal synaptic transmission nor LTP in WT visual cortical slices. Shown are relative FP amplitudes of slices incubated with 8-pCPT-cGMP (10 $\mu \mathrm{m}, 15 \mathrm{~min}$ ) without (7 slices from 3 mice) and with TBS treatment (8 slices from 5 mice).

bodies (Bidmon et al., 2004). The neuronal localization of eNOS has been a matter of debate, but the presence of the NO-forming enzyme in the endothelium of blood vessels or capillaries appears to be beyond doubt (Hopper and Garthwaite, 2006) and signaling of blood vessel-derived NO to central axons has been demonstrated previously (Garthwaite et al., 2006). In sum, the occurrence of the major constituents of the NO/cGMP signaling cascade in the visual cortex argues for a role in synaptic transmission, albeit ocular dominance plasticity, a potential functional consequence in visual cortex, was not altered under NOS inhibiting conditions (Reid et al., 1996; Ruthazer et al., 1996).

Because LTP measured in WT cortical slices was completely blocked by the inhibitor of NO receptor GC, ODQ, we conclude that NO/cGMP participates in synaptic plasticity in the visual cortex. Our findings are in line with the results by Liu et al. (2003) showing that LTP in the visual cortex was completely blocked by a cGMP kinase inhibitor, which itself did not affect basal synaptic transmission. Also, Volgushev et al. (2000) reported retrograde signaling of NO to be involved in LTP measured in the visual cortex. The involvement of NO in cortical LTP is further supported by a loss of neocortical LTP in eNOS-deficient mice (Haul et al., 1999) and by an NO-dependent component of LTP found in the barrel cortex (Hardingham and Fox, 2006), in the medial frontal cortex (Nowicky and Bindman, 1993), and in the rat auditory cortex (Wakatsuki et al., 1998). The lack of a measurable cGMP increase during LTP does not argue against cGMP as a physiological messenger because also in other tissues, physiologically effective cGMP increases are too low to be measured in the radioimmunoassay (Mergia et al., 2006). Whereas basal synaptic transmission was unaltered in the KO slices, LTP could not be induced in either of the GC-isoform $\mathrm{KO}$ animals, suggesting a contribution of both GC isoforms to LTP. To substitute the function of the missing isoform, cGMP in the form of a cGMP analog was added and resulted in restitution of LTP indistinguishable from that in WT slices. The successful recovery of LTP demonstrates that aside from the lack of the cGMP forming enzymes, all other cellular components required for potentiation of synaptic transmission are unaffected in the KO strains. Our finding that both GC isoforms have to be present for LTP expression and cannot substitute for each other is unexpected at first. Conceivably, the isoforms act in an additive manner with each GC isoform only supplying a subthreshold level of cGMP and the two together being required to surpass the threshold. Yet, this notion does not appear very likely considering that only a minor fraction (5\%) of WT NO receptor GC in smooth muscle cells is able to accomplish a substantial portion of its biological function. Alternatively, the lack of the LTP in either one of the KO mice can be explained by specific functional roles of the GC isoforms, and two distinct effects of NO/cGMP in the course of LTP expression have been suggested in several previous reports. Based on the finding that LTP induced by exogenous NO paired with a short tetanus was blocked by inhibition of NOS, Bon and Garthwaite (2003) proposed that two NO/cGMP-mediated signals are required for the induction and maintenance of LTP. In a recent report, the authors are able to demonstrate that these tonic and phasic NO signals required for LTP are generated by eNOS and nNOS, respectively (Hopper and Garthwaite, 2006). These findings perfectly match with and complete our data, suggesting the existence of two sets of the NO/cGMP signaling cascade that participate in LTP, each consisting of an NOS isoform, eNOS or nNOS, and either one of the GC isoforms ( $\alpha_{1}$-GC or $\alpha_{2}$-GC). Of course this assumption is highly speculative and requires experimental conformation. Postsynaptic as well as a presynaptic roles of $\mathrm{NO}$ and cGMP in LTP have been proposed by others in the hippocampus (Son et al., 1998; Wang et al., 2005) and in the visual cortex (Wei et al., 2002). The enhancement of the neurotransmitter release appears to be an established NO/cGMP response in the presynaptic nerve terminal (Arancio et al.,1996, 2001) whereas the function of the NO/cGMP signal in the postsynaptic neuron in the potentiation of neurotransmission is unclear (Ko and Kelly, 1999). Nevertheless, in view of our results it is tempting to speculate that the GC isoforms serve as presynaptic and postsynaptic NO receptors, respectively; although different spatial localizations of the GC isoforms targeted to subcellular compartments is also conceivable. Summing up, the requirement of both GC isoforms for LTP indicates that they are engaged in different signaling pathways. The lack of LTP in mice expressing only one of the two GC isoforms implies that cGMP formed by one GC isoform is not sufficient to induce LTP, suggesting that two NO/cGMPinduced responses have to occur coincidently to allow expression of LTP. Whether this is only the case in LTP in visual cortex or relevant for LTP in other brain areas (e.g., the hippocampus) awaits additional investigations.

The finding that both GC isoforms are mandatory for LTP in the visual cortex is the first demonstration of GC isoform-specific functional roles. This is in contrast to the vasculature, where one isoform can functionally substitute for the other (Mergia et al., 2006). The current study reveals that in the visual cortex the isoforms of NO receptor GC participate in distinct signaling cascades, which have to work in concert for expression of LTP and underlines the physiological significance of NO/cGMP signaling in synaptic plasticity. 


\section{References}

Arancio O, Kiebler M, Lee CJ, Lev-Ram V, Tsien RY, Kandel ER, Hawkins RD (1996) Nitric oxide acts directly in the presynaptic neuron to produce long-term potentiation in cultured hippocampal neurons. Cell 87:1025-1035.

Arancio O, Antonova I, Gambaryan S, Lohmann SM, Wood JS, Lawrence DS, Hawkins RD (2001) Presynaptic role of cGMP-dependent protein kinase during long-lasting potentiation. J Neurosci 21:143-149.

Artola A, Singer W (1987) Long-term potentiation and NMDA receptors in rat visual cortex. Nature 330:649-652.

Bear MF (1995) Mechanism for a sliding synaptic modification threshold. Neuron 15:1-4.

Bellamy TC, Garthwaite J (2002) The receptor-like properties of nitric oxide-activated soluble guanylyl cyclase in intact cells. J Mol Cell Biochem 230:165-176.

Bidmon HJ, Starbatty J, Gorg B, Zilles K, Behrends S (2004) Cerebral expression of the alpha2-subunit of soluble guanylyl cyclase is linked to cerebral maturation and sensory pathway refinement during postnatal development. Neurochem Int 45:821-832.

Bon CL, Garthwaite J (2001) Exogenous nitric oxide causes potentiation of hippocampal synaptic transmission during low-frequency stimulation via the endogenous nitric oxide-cGMP pathway. Eur J Neurosci 14:585-594.

Bon CL, Garthwaite J (2002) Adenosine acting on A1 receptors protects NO-triggered rebound potentiation and LTP in rat hippocampal slices. J Neurophysiol 87:1781-1789.

Bon CL, Garthwaite J (2003) On the role of nitric oxide in hippocampal long-term potentiation. J Neurosci 23:1941-1948.

Boulton CL, Southam E, Garthwaite J (1995) Nitric oxide-dependent longterm potentiation is blocked by a specific inhibitor of soluble guanylyl cyclase. Neuroscience 69:699-703.

Ding JD, Burette A, Nedvetsky PI, Schmidt HH, Weinberg RJ (2004) Distribution of soluble guanylyl cyclase in the rat brain. J Comp Neurol 472:437-448.

Ding JD, Burette A, Weinberg RJ (2005) Expression of soluble guanylyl cyclase in rat cerebral cortex during postnatal development. J Comp Neurol 485:255-265.

Garthwaite G, Bartus K, Malcolm D, Goodwin D, Kollb-Sielecka M, Dooldeniya C, Garthwaite J (2006) Signaling from blood vessels to CNS axons through nitric oxide. J Neurosci 26:7730-7740.

Garthwaite J, Boulton CL (1995) Nitric oxide signaling in the central nervous system. Annu Rev Physiol 57:683-706.

Garthwaite J, Charles SL, Chess-Williams R (1988) Endothelium-derived relaxing factor release on activation of NMDA receptors suggests role as intercellular messenger in the brain. Nature 336:385-388.

Hardingham N, Fox K (2006) The role of nitric oxide and GluR1 in presynaptic and postsynaptic components of neocortical potentiation. J Neurosci 26:7395-7404.

Haul S, Godecke A, Schrader J, Haas HL, Luhmann HJ (1999) Impairment of neocortical long-term potentiation in mice deficient of endothelial nitric oxide synthase. J Neurophysiol 81:494-497.

Hawkins RD, Son H, Arancio O (1998) Nitric oxide as a retrograde messenger during long-term potentiation in hippocampus. Prog Brain Res 118:155-172.

Hopper RA, Garthwaite J (2006) Tonic and phasic nitric oxide signals in hippocampal long-term potentiation. J Neurosci 26:11513-11521.

Huemmeke M, Eysel UT, Mittmann T (2004) Lesion-induced enhancement of LTP in rat visual cortex is mediated by NMDA receptors containing the NR2B subunit. J Physiol (Lond) 559:875-882.

Kirkwood A, Dudek SM, Gold JT, Aizenman CD, Bear MF (1993) Common forms of synaptic plasticity in the hippocampus and neocortex in vitro. Science 260:1518-1521.
Ko GY, Kelly PT (1999) Nitric oxide acts as a postsynaptic signaling molecule in calcium/calmodulin-induced synaptic potentiation in hippocampal CA1 pyramidal neurons. J Neurosci 19:6784-6794.

Koesling D, Russwurm M, Mergia E, Mullershausen F, Friebe A (2004) Nitric oxide-sensitive guanylyl cyclase: structure and regulation. Neurochem Int 45:813-819.

Liu S, Rao Y, Daw N (2003) Roles of protein kinase A and protein kinase G in synaptic plasticity in the visual cortex. Cereb Cortex 13:864-869.

Mergia E, Russwurm M, Zoidl G, Koesling D (2003) Major occurrence of the new $\alpha_{2} \beta_{1}$ isoform of NO-sensitive guanylyl cyclase in brain. Cell Signal 15:189-195.

Mergia E, Friebe A, Dangel O, Russwurm M, Koesling D (2006) Spare guanylyl cyclase NO receptors ensure high NO sensitivity in the vascular system. J Clin Invest 116:1731-1737.

Nowicky AV, Bindman LJ (1993) The nitric oxide synthase inhibitor, $N$-monomethyl-L-arginine blocks induction of a long-term potentiationlike phenomenon in rat medial frontal cortical neurons in vitro. J Neurophysiol 70:1255-1259.

O’Dell TJ, Hawkins RD, Kandel ER, Arancio O (1991) Tests of the roles of two diffusible substances in long-term potentiation: evidence for nitric oxide as a possible early retrograde messenger. Proc Natl Acad Sci USA 88:11285-11289.

Reid SN, Daw NW, Czepita D, Flavin HJ, Sessa WC (1996) Inhibition of nitric oxide synthase does not alter ocular dominance shifts in kitten visual cortex. J Physiol 494:511-517.

Russwurm M, Behrends S, Harteneck C, Koesling D (1998) Functional properties of a naturally occurring isoform of soluble guanylyl cyclase. Biochem J 335:125-130.

Russwurm M, Wittau N, Koesling D (2001) Guanylyl cyclase/PSD-95 interaction: targeting of the nitric oxide-sensitive $\alpha_{2} \beta_{1}$ guanylyl cyclase to synaptic membranes. J Biol Chem 276:44647-44652.

Ruthazer ES, Gillepsie DC, Dawson TM, Snyder SH, Stryker MP (1996) Inhibition of nitric oxide synthase does not prevent ocular dominance plasticity in kitten visual cortex. J Physiol 494:519-527.

Schuman EM, Madison DV (1991) A requirement for the intercellular messenger nitric oxide in long-term potentiation. Science 254:1503-1506.

Son H, Hawkins RD, Martin K, Kiebler M, Huang PL, Fishman MC, Kandel ER (1996) Long-term potentiation is reduced in mice that are doubly mutant in endothelial and neuronal nitric oxide synthase. Cell 13:1015-1023.

Son H, Lu YF, Zhuo M, Arancio O, Kandel ER, Hawkins RD (1998) The specific role of cGMP in hippocampal LTP. Learn Mem 5:231-245.

Volgushev M, Balaban P, Chistiakova M, Eysel UT (2000) Retrograde signalling with nitric oxide at neocortical synapses. Eur J Neurosci 12:4255-4267.

Wakatsuki H, Gomi H, Kudoh M, Kimura S, Takahashi K, Takeda M, Shibuki K (1998) Layer-specific NO dependence of long-term potentiation and biased NO release in layer V in the rat auditory cortex. J Physiol (Lond) 513:71-81

Wang HG, Lu FM, Jin I, Udo H, Kandel ER, de Vente J, Walter U, Lohmann SM, Hawkins RD, Antonova I (2005) Presynaptic and postsynaptic roles of NO, cGK, and RhoA in long-lasting potentiation and aggregation of synaptic proteins. Neuron 45:389-403.

Wei JY, Jin X, Cohen ED, Daw NW, Barnstable CJ (2002) cGMP-induced presynaptic depression and postsynaptic facilitation at glutamatergic synapses in visual cortex. Brain Res 927:42-54.

Wilson RI, Yanovsky J, Godecke A, Stevens DR, Schrader J, Haas HL (1997) Endothelial nitric oxide synthase and LTP. Nature 386:338.

Wilson RI, Godecke A, Brown RE, Schrader J, Haas HL (1999) Mice deficient in endothelial nitric oxide synthase exhibit a selective deficit in hippocampal long-term potentiation. Neuroscience 90:1157-1165. 